\title{
THE
}

\section{Introduction to Focused Issue: History of Textiles and Fashion}

Linda Welters

University of Rhode Island, Iwelters@uri.edu

Abby Lillethun

Follow this and additional works at: https://digitalcommons.uri.edu/tmd_facpubs

The University of Rhode Island Faculty have made this article openly available.

Please let us know how Open Access to this research benefits you.

This is a pre-publication author manuscript of the final, published article.

Terms of Use

This article is made available under the terms and conditions applicable towards Open Access

Policy Articles, as set forth in our Terms of Use.

\section{Citation/Publisher Attribution}

Welters, L., Lillethun, A. (2020). Introduction to Focused Issue: History of Textiles and Fashion. Clothing and Textiles Research Journal, (38)4, 227-239. https://doi.org/10.1177/0887302X20935637

This Article is brought to you for free and open access by the Textiles, Fashion Merchandising and Design at DigitalCommons@URI. It has been accepted for inclusion in Textiles, Fashion Merchandising and Design Faculty Publications by an authorized administrator of DigitalCommons@URI. For more information, please contact digitalcommons-group@uri.edu. 


\section{Introduction to Focused Issue: History of Textiles and Fashion}

\section{Linda Welters and Abby Lillethun}

Understanding the history of textiles and fashion is a component of the undergraduate curricula at International Textile and Apparel Association (ITAA) member institutions. Some faculty and graduate students specialize in the subdiscipline of historic textiles and fashion for both teaching and research. Their publications feature topics across the broad area of history related to textiles and dress. Yet, the historians among the members often find themselves on the margins of ITAA despite "historic" being one of twelve tracks for research and teaching submissions at the annual conference as well as a long-accepted category for the organization's publications.

Why do ITAA's historians perceive themselves as standing on the sidelines? One of the reasons for this perception is that the social science format of Clothing and Textile Research Journal (CTRJ) does not align with standard reporting formats in the broad discipline of history. Another problematic issue is the lack of color in the printed versions of the journal because the images of historic textiles and fashion that often accompany the articles are not as useful to readers when in black and white. The lack of color is also a detriment to ITAA's designers who wish to publish in CTRJ. A third reason is that scholars seeking historical research do not turn to the journal or to most of its 13 indexing databases, as only one is history focused and other journals and databases provide richer search results on history of textiles and dress.

It has been 28 years since $C T R J$ has devoted an issue to the historic area. In the intervening years, much has changed. Opportunities for publication in other journals have increased. Consequently, ITAA's historians are turning elsewhere to disseminate their research. 
Members are opting to submit to journals that specialize in textile and/or fashion history instead of CTRJ. Rather than abdicating historic subject matter to other journals, members researching history topics should consider publishing some of their scholarship in the organization's scholarly journal. This focused issue aims once again to draw attention to research in the history of textiles and fashion among our members and to suggest a path forward.

History is often explained as the study of the past in order to understand the present and pave the way to the future (Reeves-DeArmond et al., 2011). Thus, we divide this introduction into three parts: the past, the present, and the future. In the first section, we review how history of dress and textiles has progressed under the umbrella of "clothing and textiles," which for many years was its own subject matter area within home economics. In the section on the present, we provide a snapshot of the current situation given the acceptance of dress and textile history by a wide range of academic disciplines. Lastly, we offer suggestions to move forward with research on the history of fashion/dress and textiles within ITAA and for publication in CTRJ.

\section{The Past}

Studying the history of dress and textiles has been part of the field of home economics almost from its beginning. In the late 1890s, Ellen Swallow Richards organized a series of conferences at Lake Placid in upstate New York to define the field which was then known as "domestic science." She and her fellow teachers eventually decided on the name "home economics." At the tenth Lake Placid conference, in 1908, the American Home Economics Association was formed (Weigley, 1974). Subject matter was roughly divided into food, clothing, and shelter. In 1909, the organization began publishing the Journal of Home Economics with the standardization of courses for the bachelor's degree as an early interest. The 1911 volume included articles on what 
topics should constitute home economics courses taught at the nation's many high schools, colleges, and universities. Jane Fales (1911) presented the need for a course in historic costume. She based her rationale on the necessity of developing knowledge of artistic design and originality for those students who might enter America's burgeoning textile and fashion industry as dressmakers. She argued that "We must get the inspiration for our needed originality by studying not present day costume but that of bygone centuries" (Fales, 1911: 244). She concluded by remarking that the study of historic costume requires patient research. History of textiles did not warrant a separate course, but instead formed a component of a basic course in textiles (Crooks, 1911).

Since those early days, courses have been taught, textbooks written, research conducted, and articles and monographs published. Yet options for publishing peer-reviewed research were limited under the home economics umbrella. It was not until 1972 that AHEA launched the Home Economics Research Journal (renamed Family and Consumer Science Research Journal in 1994). Textiles and clothing educators had already branched off from AHEA in 1944, and they had begun holding their own meetings. They finally incorporated as the Association of College Professors of Textiles and Clothing in 1979 with national conferences held every third year and regional meetings occurring in the intervening years. Published proceedings included abstracts of research presentations. Leadership felt the need for a publication dedicated to textiles and clothing research. Finally, a research journal - the Clothing and Textile Research Journalbegan publication in 1982. In 1991, ACPTC changed its name to the International Textile and Apparel Association to reflect growing international membership and the globalization of the textile and fashion industry (Welters and Marcketti, 2015). 
Key journals focusing solely on the history of textiles and apparel began appearing on both sides of the Atlantic in the sixties and seventies (Welters and Lillethun, 2018). The Costume Society of Great Britain formed in 1964 and began publishing its journal Costume in 1967. The Pasold Research Fund, also centered in Great Britain, launched Textile History in 1968; at first its focus was the economic history of textiles, but in recent years it expanded to include all aspects of the history of textiles and dress. The Costume Society of America formed in 1973 and started publishing Dress in 1975. A group of scholars who studied quilts formed the American Quilt Study Group; the papers presented at their annual seminar have been published in Uncoverings since 1980. Thus, even at the launching of CTRJ, other options for publishing research on historic topics existed for ITAA members. The playing field further expanded when Berg publishers became interested in fashion and textiles at the turn of the century: Fashion Theory launched in 1997, Textile: Cloth and Culture in 2003. These have since moved to independent publishers, at present Taylor and Francis. More recently, Intellect has joined the field with an array of titles that accept historic research: Fashion, Style, and Popular Culture; Clothing Cultures; Critical Studies in Men's Fashion; Critical Studies in Fashion and Beauty; and International Journal of Fashion Studies. Expenses are kept low for this publisher with mostly online subscriptions. Springer launched an open access journal titled Fashion and Textiles in 2014 that lists "history of fashion" as acceptable content. Additional journals are appearing with regularity such as ZoneModa Journal out of Italy and the Journal of Dress History sponsored by The Association of Dress Historians located in England. This plethora of journals has created many opportunities for ITAA members to publish their research in addition to $C T R J$. 
Back in 1992, when CTRJ was just ten years old, its one-and-only focused issue on historic research topics was published as volume 10 , number $3 .{ }^{1}$ The need for a focused issue arose due to concerns from now-retired members trained as historians, specifically Virginia Gunn and Patricia Campbell Warner, who complained about the inflexibility of the American Psychological Association (APA) style used by CTRJ compared to the Chicago Manual of Style (CMS) in which historians are trained. Gunn wrote a piece for an ITAA monograph articulating the reasons why CTRJ's empirical approach to research reporting was exclusionary for historians (Gunn, 1991). In the same monograph, Welters observed that although historic topics were well represented in CTRJ and at ACPTC/ITAA meetings, as a body of researchers ITAA members had little impact on the larger landscape of historical research (Welters, 1991). Gunn herself is an authority on quilts, coverlets and needlework; she authored ten articles in Uncoverings. Warner specialized in the history of women's sports dress, and she selected Dress as her go-to journal where she published eight articles. Both Gunn and Warner published articles in the 1992 focused issue; both used the CMS reporting format as authors were able to use either APA or CMS.

The 1992 focused issue featured a total of ten articles. Additional accepted manuscripts appeared in subsequent issues. In total, 26 manuscripts had been submitted, many from active researchers who had never submitted to CTRJ before (Welters, 1992). The published articles displayed a wide variety of research areas in which ITAA members were involved, including archaeological textiles, history of dressmaking, and dye history to name a few.

As readers can see, this issue contains just four articles, $50 \%$ of those submitted. How can the steep reduction in submissions to the current focused issue be explained? It is a worthwhile exercise to examine published reports of the frequency of historic textile and clothing articles in relevant journals from 1911 until 2019. Five relevant studies have been conducted that report on 
the content of articles published in CTRJ, its predecessors, and its competitors. The first was Usha Chowdary and Esther Meacham's analysis of the changing focus of the Journal of Home Economics and the Home Economics Research Journal from each journal's founding until 1980 (Chowdary and Meacham 1983-84). The authors found that historic subject matter ranked a distant third after "textiles" at $51.4 \%$ and "consumerism" at $22.1 \%$, amounting to $9.8 \%$ of the journals' content. Lennon et al. (2001), in a survey of research trends based on three journals, found that historic dress and textiles was the fifth most frequent content area from 1980 to 1999, comprising $8.7 \%$ of content. ${ }^{2}$ A third article, published in CTRJ, focused solely on the historic subject matter area, a fact that emphasizes its importance to ITAA members (Reeves-DeArmond et al., 2011). The authors evaluated 306 articles published from the date of inception of CTRJ (1982) and Dress (1975) until the end of 2006. They looked for several measures, one of which was the percentage of articles on historic topics. While all of the articles in Dress featured historic dress subjects, only $13 \%$ of CTRJ's content fit the historic category. A fourth article (Ha-Brookshire and Hawley, 2014) reported on trends in content in CTRJ from 1993 to 2012; although their focus was on global supply chain management, they included all subject matter areas. They found that socio/psychological aspects of clothing dominated research topics. The most recent publication (Lee et al., 2020) analyzed 513 articles from 2000-2019 in two journals—Family \& Consumer Sciences Research Journal (FCSRJ) and CTRJ—for research trends. Citing ITAA's scholarship themes, the authors combined history and culture into one of ten scholarship tracks. ${ }^{3}$ The conjoining of history and culture (e.g., contemporary topics) makes it difficult to compare to the previous studies. When combined, history and culture was the theme of $9.29 \%$ of the published articles. This percentage implies a decline in publication of straight historical research since 2000 because articles on culture were included. Figure 1 
illustrates that history and culture content, which totaled 52 articles, indeed declined over the twenty years studied and that just 18 articles, or $34.6 \%$ of the total history and culture articles were published from 2010 through 2019. An interesting component of Lee et al.'s study was the inclusion of citation counts as an objective of their research. History and culture ranked near the bottom with only $4 \%$ of the citations. This finding implies that FCSRJ and CTRJ are not where scholars working in the growing arena of historical and cultural studies look for research, or choose to publish their own research.

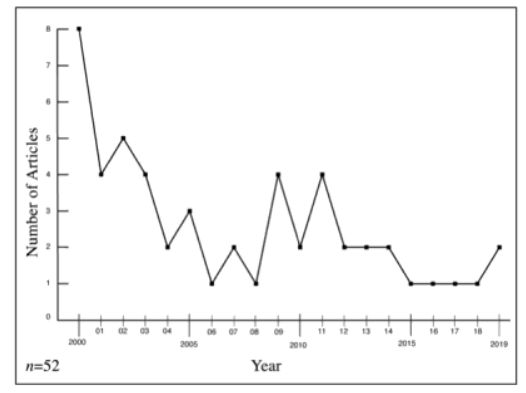

FIGURE 1. Graph showing the frequency of "culture/history" articles published in CTRJ and FCSRJ from 2000 through 2019. Created by authors with Fafar Bayat from data in Lee et al. (2020, p. 7, Table 2).

This analysis raises the following question for the historians in ITAA. Is CTRJ a place to publish historic research? Some university administrators may place value in getting published in $C T R J$ for tenure and promotion. Our goal with this focused issue is to show that ITAA members should publish at least some of their research output in CTRJ as well as making suggestions to move the historic area forward in the journal and the organization.

\section{The Present}


At the 2017 meeting in St. Petersburg, Florida, a panel on historic research was presented (Shephard et al., 2017). This led to the idea of devoting an issue of CTRJ to the history of textiles and fashion. A draft of the call for this focused issue was first circulated to the CTRJ editorial board early in 2018 for approval. The call was then issued to the membership in April of that same year with a deadline of January 15, 2019 for submission. The deadline was extended one month to February 15, 2019 to attract a larger pool of manuscripts than had been submitted by the initial deadline.

The call stipulated that submissions could "include any textile and or fashion topic that broadly falls under the umbrella of history." The guest editors further specified that the cutoff date be 1970, reflecting the opinion of American historian Michael Beschloss, who suggested that historical analysis requires "hindsight," therefore needing about 50 years of elapsed time (Beschloss 2018). This limitation may have reduced the number of submissions as many ITAA members have been researching more recent dress and textile topics that fall under the umbrella of cultural studies or ethnographic studies rather than history.

In the end, a total of eight manuscripts were received. As noted earlier, the number of submissions was low in comparison to the call for the 1992 issue. One manuscript did not fit the parameters, resulting in seven that went through the double-blind review process. Four manuscripts stuck it out through multiple revisions, and these four articles are published in this issue. As a group, they show a range of approaches to historic topics. Yet, the low number of submissions highlights one of the issues cited above, that many opportunities to publish historic research elsewhere have arisen in recent years. 
The four articles in this focused issue investigate history from British, Scottish, U. S., and Chinese contexts. The time range spans from 1046 BCE to 1961 CE. All of the authors used textual primary sources, and two employed artifact analysis of extant textiles or clothing.

David Loranger and Eulanda A. Sanders investigated British influences upon, and use of, Scottish Highland dress, that is to say kilts and tartans, and its deployment by the British for national political advantage. Their overarching goal in "The ties that bind: Britain's use of Scottish Highland dress" is to illuminate the processes of "appropriation, manipulation, and transformation" in dress with focus on the roles of identity and social control. The contentious relationship between Scotland and Britain serves as background to the British redefinition of Scottish Highland dress as a symbol of a unified kingdom, rather than a symbol of Scottish traditional culture dating to the $14^{\text {th }}$ century. The British were thus subjugating Scottish identity to the new national whole. Importantly, the work contributes new understanding of the role of textiles in the Atlantic slave trade, and specifically to the Triangular Trade that connected Britain, Africa, and the New World, notably the North American colonies and the Caribbean. Loranger and Sanders combined history, cultural studies, and material culture investigative techniques. They examined archival materials such as The Trans-Atlantic slave trade database. Three extant military kilts provided evidence that, when connected to evidence in historical records, allow the authors to explain how Scottish Highland dress delivered a wide array of meanings across time, that is as the symbol of a proud regional identity, as a marker of the enslaved in 18th-century South Carolina, and broadcast as a symbol of the United Kingdom by royal adoption.

In "L. Candee \& Co. and the U.S. rubber shoe industry," Arlesa J. Shephard presents a case study focused on a niche clothing industry that had long-lasting implications in American 
business; a key historical character of the study is Charles Goodyear whose last name lives on as the identity of a multi-brand global tire company. Readers will note that the references have been listed in two sections, that is as primary and secondary resources. To examine the introduction, rise, and decline of the rubber shoe industry in the entrepreneurial American industrial landscape of the $19^{\text {th }}$ and early $20^{\text {th }}$ centuries, Shephard utilized six archival collections and patent records. A business life-cycle model that was originally designed for contemporary application to entrepreneurial endeavors was employed to dissect and analyze this case study. Shephard thus delivers a useful descriptive structure to historians seeking to analyze a given business or business sector. The study provides views into disputes over patents for vulcanization (which allows rubber to be stable across temperature changes) and products, as well as into marketing strategies and consumer reactions to rubber products, and into labor issues such as working conditions and unionization.

In addition to archival, patent, and object-based strategies, another tried-and-true method used in historical research is content analysis (Paoletti, 1982). Jessica L. Ridgway used content analysis to examine book texts, both instructional and those for the consumer market, which provided advice on the application of the design element "line" in dress design and appearance practices. The books serve as the primary sources of the study. "The 'Use of lines in your clothing will work magic': Advice to women from 1914 to 1961 on using line to design an ideal body type" investigates how authors discussed the design element line and how they proposed that an ideal body type may be most closely achieved through its use. Ridgway shows that apparel design advice remained consistent in its directives and utilized words for body types that are distinct from those in use in the $21^{\text {st }}$ century. The study contributes to women's history, both 
to the history of women's formal education and to understanding appearance didactics offered to the American populace that intended to lead them to their "best" appearance.

The fourth article in this issue, titled "Song Brocade in the Ming and Qing Dynasties," is a descriptive study that provides a welcome focus on textile history. Kun Chen, Dan Lu, Zimin Jin, Miao Su, and Jing Jin launch their investigation from $21^{\text {st }}$-century archaeological discoveries of brocade fragments dated to the last 500 years of the Zhou dynasty (1046-256 BCE) in China. These discoveries and ones dated much later had previously led X. P. Qian to weave recreations of brocade artifacts that aimed to provide knowledge for both their conservation and further replication, and these are also used in the study. Historical texts that mention brocade textiles, some dating to the Zhou dynasty, are utilized to document and explain the long history of brocade in China including its flourishing and refinement in the Song dynasty (960-1279 CE), and its continuation as an important cultural component in the later Ming (1368-1644 CE) and Qing (1644-1911/12 CE) dynastic eras. A weave schematic and categorizations of the Song brocade variants and their motifs amplify understanding of Song brocade. Along with this new information, the investigation delivers baseline information on the topic and reveals details that are out of reach for ITAA members, and others, who do not read Chinese.

We now turn our attention to the current standing of history research in ITAA. ITAA is a multidisciplinary organization whose members have been trained in a variety of methods to conduct research. Common to all research methods is incorporation of theory. Yet, historians sometimes run into roadblocks with reviewers who downgrade an abstract or a manuscript because it does not overtly identify a theoretical model, conceptual framework, or include a section describing the method. The guest editors would like to address this problem. 
History research methodology is a prime example of inductive reasoning. To develop the question(s) or argument, the researcher reviews secondary literature. He/she then gathers evidence from primary sources such as original documents (or facsimiles) and artifacts to answer questions about past events. The literature review continues while all relevant primary sources are examined; this is done to help understand the evidence discovered in the primary sources. Only after considering all the evidence does a theory emerge as an interpretation of the evidence. Deductive research, on the other hand, begins with a theory and conducts testing to determine if data agree with the theory. This is problematic when following the historical method in that positing a theory before the research is conducted may predetermine an interpretation. History wants an interpretation, the outcome, to be revealed by the evidence, rather than shaped by a theoretical perspective. Thus, the history method is the theoretical framework.

Elaine L. Pedersen, who has published widely on theory development, articulated the many dimensions of theory in $C T R J$ (2007). She noted that "it is not uncommon for a research manuscript to be rejected because "it lacks theory"' (Pedersen, 2007, p. 119). She later provided an operational definition of theory: "Theory is a set of statements that advances knowledge by describing, explaining, or predicting the relationship between two or more constants. A theory provides order and guides research" (Pedersen, 2007, p. 123). Using this definition, she identifies "unnamed mini theories" that are common to historical research. Historians interpret primary sources and draw conclusions about events that happened in the past, but do not necessarily identify their interpretations as theories.

The previously mentioned panel presented at ITAA in 2017 on historic research focused on the importance of research methods and theory in achieving success in historic research (Shephard et al., 2017). The abstract for this panel presentation claimed that methods and/or 
theory must be clearly stated (emphasis ours). This flies in the face of pure historic research methodology. No historian includes a statement such as: "I used the historic method" in a manuscript. It is understood through the documentation of primary sources in footnotes or endnotes that the manuscript used accepted historic methods. Neither is theory spelled out for the reader. Pedersen was a member of the aforementioned panel, explaining: "Sometimes, historical research utilizes established named theories which are clearly defined in the research process and guide the development of research questions, assist in developing a framework for the study to answer the questions, and help explain research findings. Other research incorporates unnamed mini theories which consist of a hypothesis that links two or more concepts in a relational statement in the analysis stage" (Shephard et al., 2017, p. 1). We encourage ITAA members to revisit Pedersen's definition and its elaboration to facilitate a more inclusive evaluative process in their reviews of historic research.

We note that nothing in the CTRJ Guide for Authors and Reviewers mandates naming a theory, a conceptual framework, or methods section (ITAA Publications Policy Committee, 1997). The seemingly normalized structure - categorized as introduction, method, procedure, results and discussion, implications and conclusions - that derives form experimental research is not required. Further, the guide states that, "Not every question that follows will be pertinent for a particular manuscript. Nor is it assumed that a reviewer will cover every question in preparing the review," thus providing leeway for a range of approaches to a manuscript structure. However, selected aspects of the guide deserve revision to make clear that history scholarship written in the format and style used by the history field is appropriate. In our opinion, the Guide is still viable for today's membership needs; however, a few updates to facilitate historical research are needed. 
The current insistence on inclusion of a conceptual framework and methods section may stem from Pedersen's article offering guidance to CTRJ's potential authors (Pedersen, 2018). Pedersen stressed the necessity of a "conceptual or theoretical framework" and a methods section as components of a quality manuscript for CTRJ. While Pedersen, herself a historian, qualifies her breakdown of categories for historians, ethnographers, and others who collect qualitative data, this breakdown into the standard social science reporting format is misleading for ITAA's historians. In fact, the guest editors asked several of the authors for this issue to convert the organization of their manuscripts from the categories typical of social science reporting to one that more closely parallels historic research reporting.

We have observed in this introduction that sometimes "historic" and "culture" topics are combined in research calls and presentation categories from ITAA and other disciplinary organizations, as well as in research articles cited here (e. g, Lee et al, 2020). Such conflation is potentially problematic. It results in a diminishment of the role of history and culture as standalone components of the textiles and clothing field. What might be the outcome of such conflations? Comparison of standards and guidelines of the field's two accrediting bodies, Textile and Apparel Programs Accreditation Commission (TAPAC) and National Association of Schools of Art and Design (NASAD), serves as a potent example of the potential effect of such conflation.

TAPAC's Accreditation Standards “Curricula and Learning Outcomes” are not entirely TAPAC's own statements, but refer the reader to this document, "ITAA four-year baccalaureate program meta-goals 2008" (TAPAC, 2019). The ITAA meta-goals are ambiguous about history content in textiles and clothing curricula, addressing history (and culture) as follows. Under the category "Content and process knowledge" the word "historic" appears in three of the four sub- 
headings. They are: under Appearance and human behavior, "Understand and apply knowledge about the interrelationships among historic, sociocultural, and psychological factors of dress and their impact on human behavior, including the effects of life stages, change across time, and culture"; under Aesthetics and the design process, "Understand the role of historical, sociocultural [sic], and psychological factors in aesthetic expression"; and under Global interdependence, "Understand how theoretical perspectives on markets, trade, and economic development can be applied to historical and current data on production, consumption, and disposal of products" (ITAA, 2008). The first and second meta-goals listed here conjoin historic, sociocultural, and psychological content while the third uses "historical" merely as a descriptor of data. We note that in each case, references to history appear in the last bullet point, thus signaling the perceived importance of history in the listing hierarchy of the ITAA meta-goals, which in turn signals the organization's viewpoint and values. In the TAPAC and ITAA conception of an education in textiles and clothing, history content is potentially optional.

In contrast, NASAD explicitly provides guidelines for undergraduate degrees that seek 5$15 \%$ (6 to 18 credit hours of the 120 semester credit hours) of the degree in disciplinary history (NASAD 2019, 94-5, 123). ${ }^{4}$ Such guidelines allow for preparation of students in a manner that may lead to careers as historians, whether as educators or in the culture industries, while TAPAC's curricula and learning outcomes that rely on the ITAA meta-goals imply with clarity that practice as a historian is not a career option for undergraduate students studying textiles and clothing. ITAA's scholarly publication follows a philosophy in line with its undergraduate metagoals, which diminishes historic studies, the practices of historians, and fails to portend careers for them. It is no surprise, then, that $C T R J$ history content is not robust in numbers and is seldom cited. 


\section{The Future}

This introduction began by noting three issues with $C T R J$ of concern to historians. The first regards the restrictions of the APA style guide which discourages use of content notes. CTRJ's editorial board might consider allowing historians to use CMS format. That option was offered as a possibility for this focused issue; however, the guest editors decided to stay with APA format to show that it is possible to publish historic research in APA style. Other journals that publish research on historic fashion and textiles use Chicago Style Documentation II, which specifies parenthetical author-date references and a corresponding reference list that is similar to APA. Thus, it should not be that unfamiliar for historians using Chicago's parenthetical authordate references to convert to APA style. For historians who only use Chicago Style Documentation I, the flexibility of writing their research with documentation in footnotes or endnotes should be allowed. The second issue stated that CTRJ might be more attractive as a publication site to both historians and designers if the print version of the journal was published in color. Currently the online version is published in color, but not the print version. Perhaps this is a moot point should the journal move to online publication only. A third issue is to increase exposure through additional indexing in databases where historians look for published research. Among the candidates are Art Index, Arts and Humanities Database (ProQuest), and Historical Abstracts.

Regarding the standard social science style guide utilized by APA, ITAA's authors should not be required to force their historic research into that format for publication in CTRJ. Reviewers must not discount manuscripts that do not use social science format. Historians pose questions, arguments, or hypotheses in their introductions. After data/evidence is collected, 
analysis requires artful and skilled presentation of that evidence in an orderly comprehensive manner. Historians do not separate the literature review or have a subheading for method. By way of example, a historic article is discussed that comes from a journal outside the list of textiles and fashion journals mentioned above. Its topic is $18^{\text {th }}$-century wig curlers, and it was published in Winterthur Portfolio, which uses Chicago style with footnotes.

The author, Laura J. Galke, began her research with the excavation of numerous ceramic curlers for men's wigs at George Washington's childhood home in Stafford County, Virginia (Galke, 2018). She delved into related $18^{\text {th }}$-century primary sources including wills, inventories, account books, newspapers, diaries, letters, maps, wig tools, period engravings, hairdressing treatises, and portraits. She read extensively in secondary sources on the fashion for wigs in colonial British America. The primary and secondary sources are cited in a total of 298 footnotes. At 50 pages, the article is long; it is organized into an unnamed introduction and nine subheadings, none of which spell out the method. For this study, the Chicago style with footnotes allowed the author to support her argument that the Washington family "engaged in a homebased program of wig care that constituted a seminal strategy for expressing their pride of place within colonial Virginia society and their membership within the British empire dependent on the intensive labor of enslaved or servant-class members of the household" (Galke, 2018, p. 89). This argument functions as a theory, although it is not stated as such. The paper is single authored, another feature that distinguishes most historic research publications. Historic articles in $C T R J$ sometimes include more than one author, often a major professor's name, a practice that is common to social science research but not to historic research.

Two examples in the same issue of CTRJ, volume 37, number 3, illustrate the difference between an article in the standard social science format and an article in a more historic-oriented 
format. Carmen N. Keist and Sara B. Marcketti (2019) follow the social science structure to report research on patents for undergarments for stout women, organizing their manuscript to include a methods section that explained application of content analysis to patents available through Google Patents. The authors listed the primary and secondary sources together in one reference list. If in CMS, documentation of the primary sources would have been in footnotes. The only other subheadings are "results and discussion" and "conclusion." On the other hand, Soon-Young Kim and Jung Ha-Brookshire's article on the history of Korean retailing skipped a methods section by commenting on their primary sources and how they were utilized in a long introduction (2019). The article continues with analysis organized under subheadings and subsubheadings. Once again, primary and secondary sources are merged in the reference list. In the current issue, we asked two authors to separate primary and secondary sources. These articles in the current issue show that even following APA's style guide, manuscripts may be organized in a manner more conducive to traditional history reporting.

As for ITAA's historians, we have several thoughts. At present, the audience for historic research published in $C T R J$ is its own members, which is a major limitation as the scholarship gets little resonance in fields outside textiles and clothing. Research meaningful to membership, then, would make sense to submit to CTRJ. Articles could include research that might change the way history of textiles and fashion is taught: for example, the discovery that sophisticated brocades were produced in China in the second millennium BCE. Research that suggests new topics for graduate students is also useful. Almost a decade ago, historic researchers pointed out the need for more research that explores non-Western textile and dress history, that focuses on pre $19^{\text {th }}$-century topics, and "that builds upon previous work related to conservation, preservation techniques, and collections management” (Reeves-DeArmond et al., 2011, p. 228). 
Now that many subject areas such as anthropology, archaeology, history, art history, languages, visual studies, and popular culture have embraced fashion and textile history as worthy research areas, in what sectors of history might ITAA members have an edge? Students at many institutions are trained to understand the science of textiles; thus, solutions to problems that require knowledge of fibers, fabrics, finishes, and how textiles age under different conditions are of value to the entire field. Another area that taps the expertise of ITAA members is recreation of both textiles and garments from cultures where artifacts do not survive. Elizabeth Barber has long been a proponent of recreating prehistoric textiles using all relevant evidence from the archaeological record. For example, she recreated textiles of the Hallstatt culture of late Bronze Age Europe (Barber, 1994). Experimental archaeology is a broad sub-area of archaeology, and it is widely employed in the textile and dress area for discovery of process and tactile components (Barber 2003). A recent trend has been to recreate clothing of cultures that have only archaeological fragments or written records from which to envision dress. Ötzi the Iceman, the Stone Age mummy discovered frozen in the Swiss Alps in 1991 is one important example. His attire has been recreated for the edification of visitors to the South Tyrol Museum of Archaeology in Bolzano, Italy. Other examples of recreations can be found in Dressing the Past (Gleba et al., 2008). In assembling the papers for Dressing the Past, the editors acknowledged the subjective, intuitive, and tactile aspects of the textile objects. Many of the authors had backgrounds in the crafts including tailoring, weaving, knitting, needlework, and leatherwork. More than a few ITAA members possess the textile knowledge and apparel-making knowledge to engage in this research area.

Historians in ITAA can move forward by keeping abreast of new directions in the field. Lou Taylor's two books on dress history have become classics for dress and fashion historians, 
and they offer suggestions for interdisciplinary research (Taylor 2002, 2004). Following on from these landmark publications is Dress history: New directions in theory and practice that includes selected papers presented at a conference celebrating Taylor's retirement from the University of Brighton (Nicklas and Pollen, 2015). The editors identified current themes, specifically dress history beyond the elite of Euro-America and the dress history of marginalized people. The journal Textile History celebrated its fiftieth anniversary in 2019 with 13 invited essays exploring key themes and sub-disciplines in textile history (Textile History, 2019). ${ }^{5}$ These essays are "think pieces" reviewing how the journal represented various topical areas. Authors addressed needs and opportunities for further research topics and approaches.

Historical readers play a role in that they introduce new researchers to key themes and current trends for a subject area. Relevant for dress historians are The Men's Fashion Reader (Reilly and Cosbey, 2008), The Men's Fashion History Reader (McNeil and Karaminas, 2009), The Fashion History Reader (Riello and McNeill, 2010), The Handbook of Fashion Studies (Black et al., 2013), and The Anthropology of Dress and Fashion: A Reader (Luvaas and Eicher, 2019). Welters and Lillethun are preparing a third edition of The Fashion Reader, a general introduction to the history, culture, and business of fashion. While content in most of the readers focuses on contemporary dress, historical dress topics are included.

ITAA lacks a strong connection to history due to the organization's focus on social science methods and research processes. However, history is a vital and meaningful field of inquiry that serves the ITAA goal of social justice and truth as it uncovers new information related to social and political conditions of the present, which is shown in the Loranger and Sanders article in this issue. This lack of connection to history is complicated by textile and fashion programs' locations within academic structures as diverse as arts and sciences, design, 
business, human ecology, and even agriculture. History research is time consuming and the productivity standards for faculty in social science units do not allow for the expected level of productivity for a historian. Historians seek to develop a body of articles or a book-length manuscript that is a highly valued accomplishment in the field of history. The social sciences, where many textiles and clothing programs reside, fail to account for the historian's professional practice and instead (usually) measure progress toward promotion and tenure in part by the number of articles published per year. An additional issue is lack of an accepted method to recognize exhibitions that have become an extension of historic textile and costume collections. $C T R J$ could consider publishing exhibition reviews written by knowledgeable external parties that could serve as external assessment for such members.

The study of textile and fashion history informs much of what is taught and studied in ITAA's programs. Design sourcing, inspiration, and forecasting benefit from history. Behavioral aspects of the field seek to understand human life and how it is affected by change. The business components of our programs are informed by a historical perspective as well. The overarching mission of the discipline, which is to contribute to the betterment of individual lives and to society, are served by history scholarship. It is to the advancement of ITAA for members to comprehend the past, have insights into the present, and predict the future. The sweeping global change currently underway should cause ITAA to rethink its approach to what has become of the field of domestic science. Do the original values of home economics still matter, or do they need to be reconsidered for a new era? It is our argument that history should be important to ITAA and far more visible within the organization than its present status.

\section{Acknowledgements}


The guest editors thank the anonymous reviewers for their expertise in reviewing the manuscripts, Fafar Bayat for the graphic, Patricia Cunningham for reading a draft of the introduction, and Elaine Pedersen for her guidance throughout the process of guest editing this volume. We also extend appreciation to the authors who diligently responded to reviewers' and guest editors' suggestions.

\section{Notes}

1. The issue was edited by Nancy J. Owens, CTRJ's editor at the time, with assistance of an Editor's Advisory Group for the issue focused on historic textiles and costume. The group consisted of Linda Welters (Chair), Lucy Sibley, Beverly Gordon, Virginia Gunn, and Susan Davis.

2. The three journals were the Journal of Family and Consumer Sciences, Family and Consumer Science Research Journal, and Clothing and Textile Research Journal. The authors chose these journals because of their relationship to home economics and its subject-matter category of textiles and clothing.

3. The history and culture scholarship track includes the following: Cross-cultural comparisons, popular culture, critical theories, ethnic studies, feminist theory, ethnographic studies, anthropological approach, and related studies, artifact analysis, historic trends, archeological studies, historic cross-cultural comparisons, and related studies (Lee et al., 2020).

4. NASAD accredits numerous undergraduate and graduate programs in the textiles and clothing field, despite the organization's lack of program titles such as "Textiles," "Fashion," or "Merchandising." 
5. Issue 1's essays include business history, conservation, design, dress, material culture, and value. Issue 2's essays are fashion, gender, cultural heritage, dyes and dyeing, global trade, consumption, and craft.

\section{References}

Barber, E. J. W. (2003). Archaeology by experiment and reproduction. In R. Laffineur and K. P. Foster (Eds.), Metron: Measuring the Aegean Bronze Age, Proceedings of the 9th International Aegean Conference, 18-21 April, 2002, (pp. 193-195). Liège: Université de Liège.

Barber, E. W. (1994). Women's work: The first 20,000 years: Women, cloth, and society in early times. New York: W. W. Norton and Co.

Beschloss, M. (Expert guest) (2018, March 8). Presidential historian reacts to Trump's president for life idea, morning joe. MSNBC, NBC Universal. Retrieved from https://www.nbcnews.com/video/presidential-historian-reacts-to-trump-s-president-for-life-idea1180219459505

Black, S., de la Haye, A., Entwistle, J., Rocamora, A., Root, R., and Thomas, H. (Eds.). (2013). The Handbook of Fashion Studies. London and New York: Bloomsbury Academic.

Chowdhary, U., \& Meacham, E. (1983-84). Changing focus of textiles and clothing within home economics: An analysis of two professional journals. Clothing and Textiles Research Journal, 2(1), 15-18. 
Crooks, N. (1911). The content of a college course in textiles for the training of teachers, and US application in lower schools. The Journal of Home Economics (June): 222-228.

Fales, J. (1911). The value of a course in historic costume. The Journal of Home Economics (June): 243-45.

Galke, L. J. (2018). Tressed for success: Male hair care and wig hair curlers at George Washington's childhood home. Winterthur Portfolio 52 (2/3), 85-135.

Gleba, M., Munkholt, C., and Nosch, M-L (Eds.). (2008). Dressing the past. Ancient Textiles Series Vol. 3. Oxford, U.K.: Oxbow Books.

Gunn, V. (1991). A case for the historical method in clothing and textile research. In S.B. Kaiser and M. L. Damhorst (Eds.), Critical Linkages in Textiles and Clothing Subject Matter: Theory, Method and Practice (p. 139-149). Monument, CO: International Textile and Apparel Association.

Ha-Brookshire, J. E., \& Hawley, J. (2014). Trends of research published by clothing and textiles research journal (1993-2012) and outlook for future research. Clothing and Textiles Research Journal, 32 (4), 251-265. 
ITAA (2008). "ITAA four-year baccalaureate program meta-goals 2008." International Textile and Apparel Association. Retrieved from https://itaaonline.org/page/Metagoals

ITAA Publications Policy Committee (1997). Clothing and Textiles Research Journal Guide for Authors and Reviewers. Retrieved from https://itaaonline.org/page/CTRJ

Keist, C. N. and Marcketti, S. B. (2019). Supporting acts: Patents for undergarments for stout women, 1891-1956. Clothing and Textiles Research Journal, 37 (3), 200-214.

Lee, Y-A, Gam, H. J., \& Bakhshian, S. (2020). Apparel, textiles, and merchandising scholarship practices from 2000 to 2019: Analysis of FCSRJ and CTRJ. Family and Consumer Sciences Research Journal. Retrieved from https://doi-org.uri.idm.oclc.org/10.1111/fcsr.12358

Lennon, S. J., Johnson, K. K., \& Park, J. H. (2001). Research trends in textiles and clothing: An analysis of three journals, 1980-1999. Family and Consumer Sciences Research Journal, 30 (2), $117-139$.

Luvaas, B. and Eicher, J. B. (Eds.) (2019). The Anthropology of Dress and Fashion: A Reader. London and New York: Bloomsbury Visual Arts.

McNeil, P. and Karaminas, V. (Eds.) (2009). The Men's Fashion History Reader. Oxford and New York: Berg. 
NASAD (2019). National Association of Schools of Art and Design Handbook: 2019-20.

National Association of Schools of Art and Design. Reston, VA: NASAD. Retrieved from https://nasad.arts-accredit.org/accreditation/standards-guidelines/handbook/

Nicklas, N. and Pollen, A. (Eds.) (2015). Dress history: New directions in theory and practice. London and New York: Bloomsbury Academic.

Paoletti, J. B. (1982). Content analysis: Its application to the study of the history of costume. Clothing and Textiles Research Journal, 1, 14-17.

Pedersen, E. L. (2007). Theory is everywhere: A discourse on theory. Clothing and Textiles Research Journal, 25 (1), 106-128.

Pedersen, E. L. (2018). Writing quality manuscripts for the Clothing and Textiles Research Journal. Clothing and Textiles Research Journal, 36 (1), 45-53.

Reeves-DeArmond, G., Ogle, J. P., \& Tremblay, K. R., Jr. (2011). Research and theory trends in historic dress and textiles research: An analysis of Clothing and Textiles Research Journal and Dress. Clothing and Textiles Research Journal, 29 (3), 216-231.

Reilly, A. and Cosbey, S. (Eds.) (2008). The Men's Fashion Reader. New York: Fairchild. 
Riello, G. and McNeill, P. (Eds.) (2010). The Fashion History Reader: Global Perspectives. New York: Routledge.

Shephard, A., Green, D. N, Mamp, M., Marcketti, S, and Pedersen, E.L. (2017). Achieving success in historic research: The importance of methods and theory. International Textile and Apparel Association (ITAA) Annual Conference Proceedings. 17. Retrieved from https://lib.dr.iastate.edu/itaa_proceedings/2017/presentations/17

TAPAC (2019). Curricula and learning outcomes in Accreditation Standards. Textile and Apparel Programs Accreditation Commission. Retrieved from https://itaaonline.org/mpage/TAPAC26

Taylor, L. (2002). The study of dress history. Manchester and New York: Manchester University Press.

Taylor, L. (2004). Establishing dress history. Manchester and New York: Manchester University Press.

Textile History (2019), 50 (1 \& 2).

Weigley, E. (1974). It might have been euthenics: The Lake Placid conferences and the home economics movement. American Quarterly, 26(1), 79-96. doi:10.2307/2711568 
Welters, L. (1991). Historical research in textiles and clothing: a position paper. In S.B. Kaiser and M. L. Damhorst, eds. Critical Linkages in Textiles and Clothing Subject Matter: Theory, Method and Practice. Monument, CO: International Textile and Apparel Association. Pp. 129138.

Welters, L. (1992). Introduction. Clothing and Textile Research Journal, 10 (3), 1-2.

Welters, L. and Lillethun, A. (2018). Fashion History: A Global View. London and New York: Bloomsbury.

Welters, L. and Lillethun, A. (Eds.) (2021). The Fashion Reader, $3^{\text {rd }}$ edition. London and New York: Bloomsbury.

Welters, L., \& Marcketti, S. (2015). "History of the textiles and apparel discipline.” In Envisioning Textile and Apparel Research and Education for the $21^{\text {st }}$ Century edited by Jung HaBrookshire and Karen LaBat. Monograph \#11, ITAA: 11-15. Retrieved from https://cdn.ymaws.com/itaaonline.org/resource/resmgr/Publications/ITAA_Monograph_11.pdf 